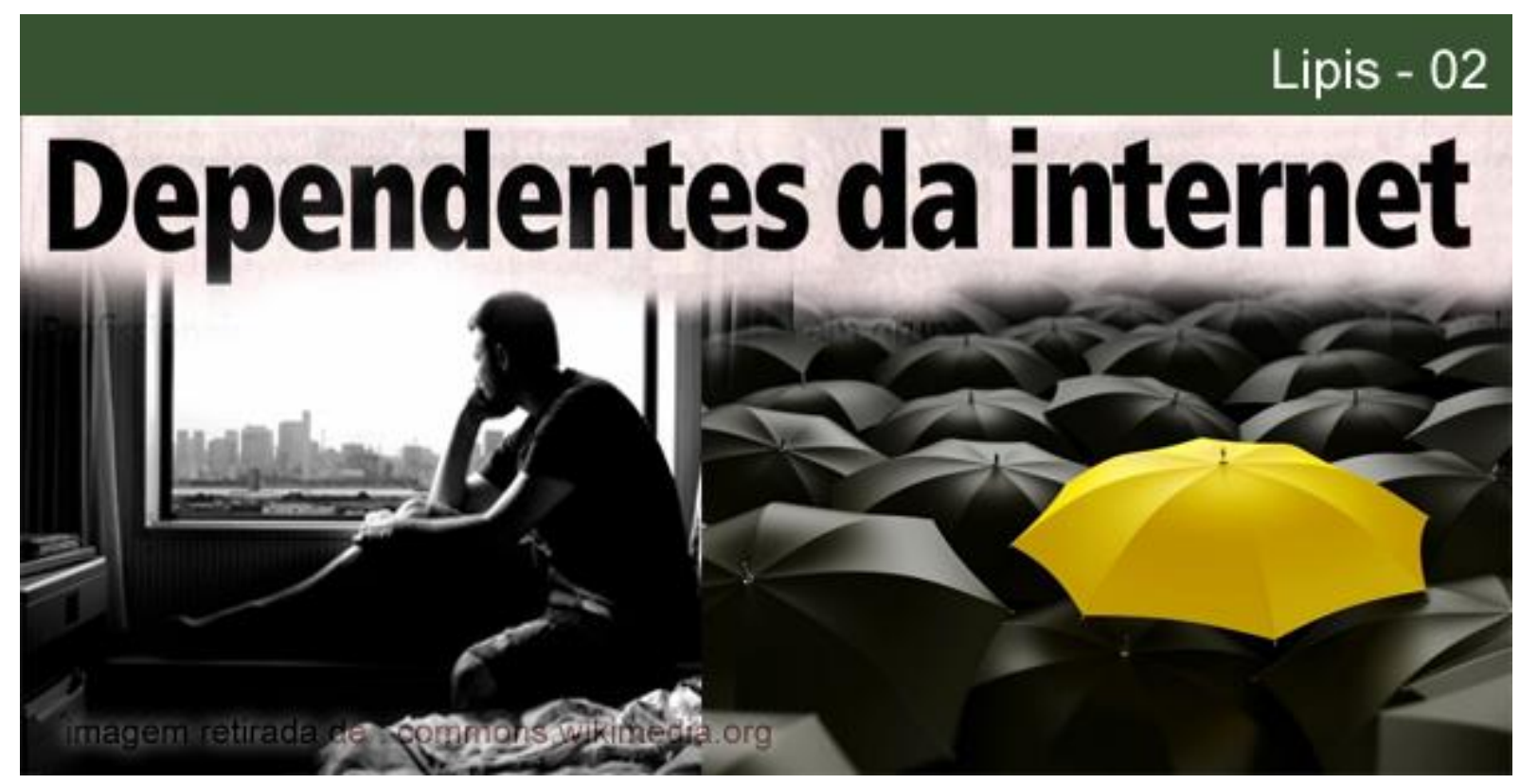

\title{
DEPENDÊNCIA DA INTERNET: SINAL DE SOLIDÃO E INADEQUAÇÃO SOCIAL?
}

\begin{abstract}
Maria Vittoria Maffei Manno
Doutora em Jurisprudência pela Universidade Estadual de Milão. Psicóloga especialista em Psicologia Clínica pelo Centro Universitário Luterano de Palmas CEULP/ULBRA. E-mail: mvittoriamanno@ gmail.com.

\section{Carlos Mendes Rosa}

Professor Adjunto do curso de Psicologia, do Programa de Pós-Graduação em Ensino em Ciências e Saúde e em Prestação Jurisdicional e Direitos Humanos (ESMAT) da Universidade Federal do Tocantins (UFT). Doutor em Psicologia pela Pontifícia Universidade Católica (PUC-Rio). Pesquisador do Laboratório Interdisciplinar de Pesquisa e Intervenção Social (LIPIS) da PUC-Rio. E-mail: carlosmendesrosa@gmail.com.
\end{abstract}

Resumo: Este artigo objetiva caracterizar prováveis motivos e apontar algumas consequências da utilização exagerada da internet como veículo de agenciamento das subjetividades na atual cultura. Procura mostrar como as relações interpessoais e as formas de interagir se modificaram com o advento das tecnologias digitais, transformando de forma significativa a expressão das individualidades; como um sentimento de inadequação social pode facilmente levar à procura de uma forma de socialização mais fácil, através do espaço virtual, arcando, porém, com o risco de tornar o sujeito dependente das redes sociais. Reflete acerca da motivação que leva à superexposição dos sujeitos no cenário contemporâneo e as mudanças que tais comportamentos ocasionam nos relacionamentos sociais e afetivos.

Palavras-chave: Internet. Solidão. Relacionamento. Psicanálise.

\section{INTERNET DEPENDENCE: SIGN OF LONELINESS AND SOCIAL INADEQUACY?}

Abstract: This article aims to characterize likely reasons and point out some consequences of excessive use of the internet as a vehicle for brokering of subjectivities in the current culture. It seeks to show how the interpersonal relations and ways to interact have changed with the advent of digital technologies, altering considerably the expression of individuality; as a feeling of social inadequacy can easily lead to the search for a form of socializing easier, through the virtual space, bearing, however, with the risk of becoming dependent on the social networks. It reflects about the motivation that leads to the overexposure of the subjects in the contemporary setting and the modifications that these behaviors cause in social and affective relationships.

\section{POLÊM!CA $\mid$ LABORE (}

Polêmica - Revista Eletrônica da Uerj - Rua São Francisco Xavier, 524, $1^{\circ}$ andar

bloco D, sl.1001 • Tels.: +55 21 2334-4088/4087 • http://www.e-publicacoes.uerj.br/index.php/polemica/index http://www.labore.uerj.br • laboreuerj@yahoo.com.br 
Keywords: Internet. Loneliness. Relationship. Psychoanalysis.

\section{Introdução}

A vida de hoje é cada vez mais influenciada pela tecnologia da web e grande parte de nossas ações cotidianas, atividades lúdicas, de trabalho e até relacionamentos significativos são realizadas através das redes sociais. A Internet é, sem dúvida, um instrumento útil, eficaz e, em alguns casos, indispensável, mas acontece que mais e mais pessoas perdem de vista a linha entre o "real" e "realidade virtual", fazendo aparecer novas sintomatologias que encontram sua "satisfação" só e unicamente online.

O ambiente virtual oferece a possibilidade de evitação das frustrações pela via da vivência individual. Existe uma espécie de materialização dos pensamentos, num movimento de construção e reconstrução continua dos indivíduos. Já não é mais necessário criar desejos, pois estes se encontram prontos e de fácil acesso. Ao sair desse mundo de fantasia, o inevitável choque com a realidade só faz reforçar a opção pela virtualização como ambiente do prazer. Então, tais sujeitos se refugiam em suas realizações digitais, com identidades fantasiadas, explorando sem limites o amplo espaço virtual, fazendo com que as identidades não se esvaziem vertiginosamente e, dessa forma, possam prolongar a sensação de gozo (COLVARA, 2007 apud DAL CIN, 2013).

Neste artigo, tecemos algumas considerações, à luz da abordagem psicanalítica, enfatizando a importância do ambiente na construção subjetiva, de quais são as dinâmicas da sociedade contemporânea, partindo do pressuposto que "a Psicologia individual é desde o início Psicologia social” (FREUD, 1921). Isso sugere que conceitos de normalidade e de psicopatologia mudem em função do contexto observado. Os modelos teóricos de referência desta análise da sociedade atual são as abordagens lacaniana e freudiana.

\section{A vida virtual}

Na obra de Freud, sobretudo a partir de 1920, com a introdução do conceito de pulsão de morte, a felicidade torna-se um sonho humano fatalmente destinado à frustração. Em outras palavras, para Freud (1921) a felicidade é impossível porque, ao defini-la, o indivíduo se coloca na posição do neurótico clássico, incapaz de superar o drama edipiano. Ou seja, o que significa ser feliz para o neurótico? Poder ter a mãe só para si.

\section{POLÊM!CA $\mid$ LABORE}


Para que o indivíduo possa se inserir no campo que Lacan (1946) chamará de grande Outro, o campo da cultura, cuja estrutura básica é a linguagem e suas leis, ele deve necessariamente abdicar de parte de suas tendências pulsionais, o que cria um conflito eterno entre o indivíduo e a pulsão.

Com a definição do conceito de grande Outro Lacan pretendeu abarcar num único movimento teórico as diversas formas através das quais a palavra nos constitui, desde a cultura (essencialmente feita de linguagem) até o discurso familiar. Do ponto de vista lacaniano, nada mais somos do que o efeito da incidência da linguagem sobre nossos corpos e o que queremos é poder ter acesso a um gozo pleno, que não obstante não existir, é suposto pelo neurótico, em sua fantasia, encontra-lo em algum lugar (NAPOLI, 2014).

Na civilização de Freud, o desconforto decorre de uma incompatibilidade fundamental entre o princípio do prazer e o princípio da realidade. Falando do princípio do prazer, Freud (1929) diz que ele "domina o trabalho do aparelho psíquico desde o início; [... ], no entanto, seu programa está em conflito com o mundo inteiro. [... ] é absolutamente impossível”. Os homens, portanto, esmagados pelo peso do princípio da realidade, renunciam a uma parte do prazer, para ganhar na segurança, escolhendo fazer parte da civilização. É deste conflito entre os dois programas, desta impossibilidade de realizar o programa do princípio do prazer, sob o peso da realidade externa, que nasce este incômodo, este mal-estar. Formações neuróticas, nessa dinâmica, se formam como retorno de "removido", que pode ser definido como o que é incompatível em relação à sua representação ideal, em relação com o programa da civilização, sob a forma de desejo. Essas produções resultam, assim, do retorno removido que, inexoravelmente, retornando, cria essa tensão entre Lei e desejo, o que não existiria sem a presença da mesma Lei.

Neste sentido, o desejo é da ordem do simbólico, uma vez que para existir precisa do Outro. Na verdade, como diz Lacan (1946) o inconsciente é estruturado como uma linguagem e suas modalidades de expressão, como sintomas, lapsos, e outros, são formações da linguagem: estão, portanto, sob a hegemonia do registro simbólico.

Lacan atribui uma grande importância aos discursos de pais e educadores para formação daquela criança que virá a ser nosso paciente adolescente. “A criança quer ser o desejo do desejo da mãe", logo, o falo (poder) dela; do outro lado, Lacan resgata a figura do pai, denominando "lei do pai" a necessidade que o pai tem de se interpor como delimitação na simbiose mãe/bebê.

\section{POLÊM!CA $\mid$ LABORE}


A associação em grupos é uma necessidade fundamental para os seres humanos, mas, enquanto no passado as comunidades eram reais e geograficamente localizadas, hoje as pessoas pertencem a comunidades virtuais. Como bem destaca Bauman, no seu livro Amor líquido: sobre a fragilidade dos laços humanos (2004), os laços de uma sociedade agora se dão em rede, não mais em comunidade. Dessa forma, os relacionamentos passam a ser chamados de conexões, que podem ser feitas, desfeitas e refeitas, dependendo da vontade do sujeito. Ao mesmo tempo em que as pessoas buscam o afeto, existe o medo de criar um sentimento mais profundo que provoque uma imobilidade num mundo que é movimento permanente.

Comunidades reais têm existido para oferecer um lugar seguro aos indivíduos que a elas pertencem, em detrimento da liberdade individual e em obediência às regras da mesma comunidade. Mas o que se vê nos dias de hoje, ao contrário da busca de segurança, é um forte desejo de independência, de mudança, e de inconformidade. Nos contextos virtuais, os indivíduos têm muito mais liberdade; eles podem escolher quem eles querem ser, qual identidade para se apresentar e como querem construir sua rede de relacionamentos: o preço a pagar por esta grande liberdade, no entanto, é a insegurança. Os laços construídos são instáveis, inseguros e podem ser quebrados facilmente.

Anonimato ou "pseudonimato" são os contextos virtuais normais: usualmente, mesmo em comunidades muito unidas, é difícil rastrear o nome verdadeiro, a verdadeira localização geográfica, a aparência física, o tom de voz ou outras informações de identificação de quem está por trás da tela. Esta possibilidade de se esconder completamente é muitas vezes entendida como se fosse uma fonte de "liberdade" e de "maior possibilidade de expressão".

Disso nos fala Castells, em seu ensaio acerca da sociedade em rede, ao analisar o impacto que estas mudanças de comportamento trazem para a nossa cultura, como o fato de a pessoa se sentir mais à vontade tecendo um comentário anônimo em um fórum do que conversando pessoalmente com uma outra pessoa (CASTELLS, 1999).

Vários estudos (GREENFIELD, 1999; YOUNG, 2007; SHAW, BLACK, 2008), porém, mostraram que todo este anonimato, na verdade, está relacionado com solidão, vazio, fraqueza e que existe uma correlação entre baixa autoestima de um lado e o uso abusivo da internet do outro. Alguns tipos de interação, como se ambientar num espaço novo e diferente (a faculdade, o trabalho), podem provocar um sentimento de inadequação social que facilmente leva à

\section{POLÊM!CA $\mid$ LABORE}


procura de uma forma de socialização mais fácil, através do espaço virtual. O que de outro lado pode levar ao risco do sujeito se tornar dependente de redes sociais.

O usuário do computador é uma metáfora perfeita desta mudança: aberto para liquidez online, mergulhando no fluxo de ligações e conexões, mas solitariamente fechado em seu próprio quarto ou, pior ainda, hipnotizado com os olhos fixados na tela. Reuniões de rede, "amigos" em redes sociais e blogs, jogos online e, em geral, qualquer contato ou conexão, em caso de comportamento viciante, servem muitas vezes como reforço narcisista e conferem ao indivíduo habilidades que ele queria ter na vida real. $O$ sujeito se coloca nesse registro imaginário que não indica necessariamente um encontro com o Outro, mas, ao contrário, permite o distanciamento da relação e o gozo solitário, em um mecanismo de glorificação do Outro e da relação com o Outro, um dos modelos de expressão da internet. Desta forma, poderá se desfrutar sem risco a relação com seu próprio desejo, porque um novo relacionamento pode substituir de forma quase automática um anterior, fora dos limites de espaço e tempo.

Poder se conectar a partir de sua própria mesa, ou de qualquer parte e a qualquer momento, graças aos dispositivos móveis de acesso como celulares e tabletes, supera os limites que se colocam em relação aos outros. Para reforçar o sentimento de ausência de limite temos a ideia, que muitas vezes se reflete na prática, de que dentro da web você pode encontrar tudo o que você está procurando: um conhecimento ou informação em relação a um determinado tópico pode ser pesquisado e procurado infinitamente na Internet até você encontrar o que se conforma com o agrado (gozo) e a expectativa inicial. A rede permite que você procure por qualquer coisa na qual você possa e deseje se identificar, mas só enquanto já idêntico a si mesmo, através de uma identificação imaginária, idealizante, no lugar de simbólica. É desse jeito que nascem sites pró-anorexia, de grupos extremistas, de jogos violentos, entre outros.

Echeburúa et al (1998) referem que o grupo mais vulnerável a adicção à Internet é composto de pessoas introvertidas, com baixa autoestima e com vida familiar frustrante, que são capazes de criar um mundo virtual que compensa a insatisfação do mundo real.

Muito do que se vê de problemático entre as pessoas adictas à Internet são os mesmos transtornos que observamos em pessoas sem a Internet: o jogo, as compras, o sexo, etc. Isso nos remete à outra consideração importante: seriam manifestações anômalas que nascem com a nova tecnologia da Internet ou as condutas anômalas já existem e essa nova tecnologia apenas propicia novas manifestações?

\section{POLÊM!CA $\mid$ LABORE}


Segundo Lacan, para a maioria das pessoas a ciência se reduz àquilo que ela oferece, isto é, se reduz aos "artefatos de consumo: televisão, celulares, a viagem à lua, e mais uma vez a viagem à lua" (LACAN, 1974, p. 67). Reflete ainda que os gadgets providos pelas novas tecnologias dificilmente não se tornariam objeto massivo de consumo dos sujeitos contemporâneos. Isso ocorre por conta da necessidade que muitos sujeitos têm de consumir compulsivamente artefatos que os mantenham satisfeitos parcialmente, como forma de afastar a insatisfação fundante que consome a todos.

No caso da internet, especificamente, existe ainda mais um fator importante nessa utilização compulsiva. O fato inescapável que a grande rede é constituída, basicamente, por texto e imagens. Aqui podemos afirmar com Birman (2006) que existe em nossa sociedade um excesso de pulsão com o qual o sujeito contemporâneo tem dificuldade de lidar no nível do simbólico, uma espécie de "preguiça" de elaborar ou refletir sobre determinadas questões que tragam mal-estar. Nesse sentido, os textos banais e mastigados da internet servem como refúgio seguro e cômodo para estes sujeitos. Pois ali, nada precisa ser elaborado ou pensado, apenas engolido (ROSA, ZAMORA, 2012).

Em relação à imagem, Certeau (1994) já nos informava que a contemporaneidade nos leva a viver muito mais no registro do imaginário, no entanto, paradoxalmente, podemos dizer que com a internet ocorreu o mesmo que com o fordismo no início do século passado, foi o início e o fim da imaginação, tudo ao mesmo tempo. Porque no mesmo momento em que somos bombardeados por uma torrente de imagens que nos capturam e seduzem, também somos isentos da necessidade de imaginar qualquer outra coisa, pois tudo que desejamos ou sonhamos já se encontra ali, à disposição nos escaninhos virtuais.

Isto seria válido desde o sapato, geladeira e bolsas às fantasias sexuais uma vez que através da Internet, as fantasias sexuais das pessoas podem ser exercitadas bem mais facilmente. Ao navegar pela web, podem-se encontrar sites e salas de bate-papo que são criadas para encorajar os usuários a se engajarem explicitamente numa conversa de cunho erótico, ou até mesmo em relações sexuais casuais.

A Internet representa um incrível meio de comunicação, pesquisa, diversão, expressão e interação. A facilidade de acesso e a variedade de conteúdos até então difíceis de encontrar, senão inacessíveis, aumentam consideravelmente a atratividade da tecnologia.

\section{POLÊM!CA $\mid$ LABORE}


Encontrar o que procuramos, em especial se for uma coisa difícil de achar, é muito estimulante e isso confere grande influência e poder à internet. De forma especial, os jogos na rede virtual contêm outros elementos muito atrativos e estimulantes, como desafio, antagonismo, competição, anonimato e, em muitos casos, recompensa. De outro lado, além de favorecer a comunicação e a busca de informações, a Internet é uma importante ferramenta de contato social. Os benefícios decorrentes do uso das redes sociais e dos aplicativos de comunicação instantânea são mencionados por parte de sujeitos mais tímidos e inibidos como um grande mecanismo de ajuda.

Temos, porém, várias causas que podem levar ao seu uso problemático: transformação compulsiva de um comportamento normal, um modo diferente de praticar adicções préexistentes (jogo, sexo), um veículo de expressão anômala de outros transtornos emocionais (transtornos afetivos) ou, finalmente, um modo de compensar dificuldades adaptativas no espaço social real (transtornos de socialização, fóbicos, etc.).

Em $O$ mínimo $E u$, Lasch (1984) explica: “O eu mínimo ou narcisista é, antes de tudo, um eu inseguro de seus próprios limites, que ora almeja reconstruir o mundo a sua própria imagem, ora anseia fundir-se em seu ambiente numa extasiada união" (p. 12).

O narcisista precisa ser admirado para poder alimentar sua própria autoestima, ele precisa ter sempre um público cativo que o admire e reverencie. Apesar de demostrar uma ilusória independência de "laços familiares e de pressões institucionais [...] isso contribui para a sua insegurança, que ele só poderá superar vendo o seu 'ego grandioso' refletido nas atenções dos outros ou ligando-se àqueles que irradiam celebridade, poder e carisma" (LASCH, 1983, p. 30-31).

A recompensa, a gratificação das redes sociais, como ter muitos "seguidores" e muitas “curtidas", é outro fator que pode contribuir para dependência, já que é uma forma de conseguir, rapidamente, aquela sensação de se sentir amado e admirado, obtendo prazer de forma fácil e rápida.

Finalmente, mas não menos importante, é preciso ressaltar o papel de estímulo de consumo de produtos, imagens e serviços. Se tomarmos o fato de que a maneira como a sociedade atual molda seus membros é ditada primeiro e acima de tudo pelo dever de desempenhar o papel de consumidor (BAUMAN, 2004), poderemos conceber que a Internet

\section{POLÊM!CA $\mid$ LABORE}


atende plenamente a esse apelo consumista e espetacular da sociedade atual. Algo que também cria quadros graves de dependência.

Não sem razão que a utilização patológica da Internet nos novos manuais psiquiátricos (DSM V, por exemplo) se encontra na categoria das compulsões, ainda que muitos desses usos possam ser considerados como quadros perversos.

Em casos extremos foi detectado também o possível surgimento de outro transtorno que recentemente foi identificado e recebeu o nome de nomofobia. A palavra nomofobia tem origem do termo inglês "No MobilePhobia", que significa sem (telefone) móvel. Trata-se de um termo relativamente recente usado para descrever a sensação de angústia que surge quando alguém se sente impossibilitado de se comunicar, quando está sem o seu celular (mobile) ou sem outro dispositivo que lhe permita se conectar com o mundo. Segundo pesquisa da empresa de segurança inglesa SecurEnvoy, em 2012, cerca de 76\% dos jovens britânicos entre 18 e 24 anos sofriam do mal e alguns chegavam a ter dois ou mais aparelhos para garantir de estar sempre online. Os sintomas são ansiedade, medo, até ataques de pânico ao sair de casa sem celular que podem levar aos outros efeitos colaterais, clássicos de dependência: náuseas, tonturas, sudorese, dificuldade de respirar, dores no peito, e aceleração dos batimentos cardíacos.

A constatação da presença reiterada destes fenômenos foi o motivo da elaboração do presente artigo, para a composição do qual foi realizada uma pesquisa qualitativa de tipo investigativo através de casos baseados na história de pacientes que procuraram atendimento no Serviço Psicológico de uma Universidade de Palmas-TO, com queixas de insegurança, falta de entrosamento com os colegas da faculdade, falta de foco no estudo e dificuldade em se relacionar sentimentalmente.

Os dados utilizados foram vinhetas clínicas, ou seja, fragmentos de falas de pacientes, relatos de sonhos e de angústias, de eventos considerados fracassos e/ou vitórias. Foram selecionados alguns temas significativos, para serem comentados, utilizando como referenciais teóricos os fundamentos da psicanálise. Foram, enfim, elaboradas as considerações finais associando-as à fundamentação teórica que serviu de referência para análise do estudo.

\section{Adolescência contemporânea virtualizada}

A adolescência é o momento em que, pela primeira vez, o sujeito é atingido pela separação. O bebê nasce, e entra no campo da língua com o significado do Outro, no sentido de

\section{POLÊM!CA $\mid$ LABORE}


que apenas corresponde, de acordo com as expectativas dos pais, ao desejo do progenitor. Adolescência é a idade em que o sujeito, pela primeira vez, se questiona sobre a relação entre o desejo dos outros e seus próprios, e, dada a impossibilidade da sua coincidência, o sujeito, ao assumir o próprio desejo, terá de passar por um movimento de separação do outro (responsabilidade). Essa dinâmica, fundamental na adolescência, vai ressurgir cada vez que o assunto será engajado na contratação de seu próprio desejo e é vivenciada pela maioria dos adolescentes de uma forma exacerbada, reunindo as dificuldades da separação e da solidão. Isso se observa, especialmente, na cidade de Palmas, onde grande parte da população estudantil se desloca do interior, deixando família, amigos e a vida mais despreocupada.

Ter computador e Internet como ferramenta de uso diário, habitual e contínuo, não representa, em si atividade danosa, já que abre inúmeras possibilidades de usufruir de informações infinitas, de aprender, explorar a própria criatividade e comunicar-se com outras pessoas. Como na maioria das atividades, o diagnóstico do uso compulsivo da Internet diz respeito aos limites entre o uso inócuo e sadio, e o aparecimento de consequências nocivas e diretas dessa atividade, quando exercida em excesso, que comprometem o uso de seu tempo ou suas atividades sociofamiliares. Nesse sentido, foi criada, recentemente, a expressão "tempo de tela" para mensurar a quantidade de horas que passamos em frente aos dispositivos eletrônicos de acesso à rede virtual. Podemos trazer aqui o exemplo de alguns pacientes que passam mais horas do seu dia em frente a uma dessas "telas" do que fazendo qualquer outra atividade como dormir, comer e socializar.

Alguns autores acham que a Internet permite às pessoas exercitarem traços ocultos ou reprimidos de suas personalidades, permite exibir online uma personalidade diferente, em maior ou menor grau, da personalidade habitual da experiência cotidiana (SANCHEZ, 2001).

Assim, as características que formam os vínculos interpessoais na Internet favorecem o comparecimento de novas facetas da personalidade, principalmente se levarmos em conta as pessoas que sofrem profundas sensações de ansiedade em situações sociais concretas e, no relacionamento pela Internet, experimentam sensações menos ansiosas e adotam posições sociais mais satisfatórias.

Este aspecto foi evidenciado claramente em várias sessões nas quais pacientes manifestam sua satisfação pelo sucesso e pela leadership conquistada através dos jogos, e nas

\section{POLÊM!CA $\mid$ LABORE}


redes sociais, em clara contraposição com os sentimentos de perceptível inferioridade manifestados em consequência das frases muitas vezes depreciativas dos colegas de curso.

Esta alternância de sentimentos contraditórios faz naturalmente que a maioria dos pacientes comece a se dedicar exageradamente aos jogos que satisfaçam sua autoestima e seu amor próprio, em detrimento do tempo dedicado às atividades sociais, profissionais ou escolares que envolvem contato interpessoal, por medo de críticas, desaprovação ou rejeição.

Isto ocasiona uma reação de profundo descontentamento consigo mesmo, sentimentos de culpa devido a não estar respondendo às expectativas dos pais e deles mesmos, tais como tornar-se bons alunos e bons profissionais no campo escolhido.

Em particular chamou a atenção o caso em que esta insatisfação, junto a uma "ameaça" de começo de namoro, criou a profunda crise que levou o estudante a procurar ajuda psicológica. Ao longo das sessões ficou muito clara a luta interna do paciente nesta sua mudança de foco: nas primeiras conversas o assunto se limitava quase completamente às dificuldades e aos sucessos obtidos durante as "batalhas" digitais; aos poucos o espaço foi tomado pelas incertezas e as dúvidas sobre "engatar um namoro com uma menina que gosta de mim", até chegar, um dia, no final de uma sessão, a proferir a frase: "percebeu que não falei de jogo nem uma vez, hoje?". Aos poucos, ficou evidente a luta interior do paciente para tentar superar os obstáculos que estava enfrentando por começar uma relação sentimental; o medo de se entregar a um contato concreto e verdadeiro, em contraposição à alegria de experimentar uma sensação nova, desconhecida, mas que estava abrindo horizontes cativantes e sedutores.

Foi neste cenário de indecisão, que o paciente relatou se sentir muito inseguro por ter aceitado um convite para um piquenique com a namorada. Quando questionado sobre qual perigo existiria em um piquenique na praça, respondeu com uma frase emblemática: "Piquenique é muito íntimo! Muito mais íntimo que uma transa!". Afinal, pode-se transar calado, mas passar duas ou três horas sentado numa praça conversando, olho no olho com uma moça de quem estamos começando a gostar, pode parecer uma barreira intransponível.

Depois deste primeiro passo, e do êxito do piquenique, cada sessão marcou um pequeno avanço na construção dos relacionamentos na vida real do paciente. Sempre mediadas pela presença real da analista, as interações como o mundo real passaram a fazer mais sentido.

Aos poucos, começou a relatar o auxílio aos colegas com dificuldades em disciplinas que ele estava dominando bem, o que lhe permitiu se aproximar de outras pessoas, mantendo a

\section{POLÊM!CA $\mid$ LABORE}


posição de liderança e de força que tanto satisfaz seu lado narcisista. A sensação de ser querido e bem aceito pelos colegas "reais" que estava auxiliando fez com que adquirisse sempre mais confiança em si mesmo e começasse a aceitar as brincadeiras, às vezes maldosas, daqueles outros colegas apelidados de "aqueles quatro ou cinco chatos" cujas zombarias tinham tanto perturbado e abalado sua autoestima no início da sua vida universitária.

\section{Conclusão}

A presente construção quis destacar os riscos para a pessoa e, especialmente, para os sujeitos mais vulneráveis, como as crianças e adolescentes, de uma tecnologia tão poderosa e penetrante como a da Internet. Foram abordados apenas aqueles aspectos que são uma fonte potencial de psicopatologias, as quais levam a sintomatologias peculiares polimorfas.

$\mathrm{Na}$ Internet se amenizam os protocolos e condicionamentos culturais que habitualmente oprimem os vínculos sociais. Muitas vezes só isso é o que deseja o internauta tímido ou ansioso social. As diferenças individuais e socioculturais que alimentam a fobia e o medo do contato interpessoal direto e real diminuem e recebem aceitação maior na Internet.

É indiscutível que a maioria das pessoas que têm um relacionamento psicótico com a Internet normalmente já apresenta uma acentuada fragilidade pessoal (baixa autoestima, baixa tolerância à frustração, evitação social) e que a rede mundial pode proporcionar diminuição do estresse e do medo da vida real. Entretanto, ao passo que esses internautas se refugiam paulatinamente no mundo virtual e se livram das experiências de vida, começam a exibir características mais intensas e diferentes das que apresentavam inicialmente. Passam, de forma inconsciente, a desenvolver comportamentos mais específicos, a trocar a vida real pela virtual, porque encontram prazer e satisfação no mundo anônimo atrás da tela, onde podem assumir qualquer personalidade, deixando para trás a sociedade que os assusta.

Em casos extremos, os pacientes entram numa espiral que os leva a não se alimentar regularmente, perder o sono, não sair mais de casa, ter prejuízo no trabalho e nas relações pessoais, se relacionando somente com conhecidos do mundo virtual.

Associando estas características da comunicação interpessoal na Internet, com os limites pessoais impostos por alguns comportamentos denominados de transtornos sociais (Fobia Social, Transtorno de Ansiedade Social e Transtorno da Pessoalidade por Evitação), será válido supor que as pessoas que sofrem algum tipo de mal-estar nas interações sociais no

\section{POLÊM!CA | LABORÉ}

Polêmica - Revista Eletrônica da Uerj - Rua São Francisco Xavier, 524, $1^{\circ}$ andar

bloco D, sl.1001 • Tels.: +55 21 2334-4088/4087 • http://www.e-publicacoes.uerj.br/index.php/polemica/index http://www.labore.uerj.br • laboreuerj@yahoo.com.br 
espaço físico real, podem manter relações plenas e satisfatórias no espaço virtual da Internet. Para o usuário da Internet não há sofrimento no contato social, mas, ao contrário, permite-se que satisfaça suas necessidades de autoestima e gratificação social.

Pelo que foi visto, é lícito esperar que as pessoas que não tenham adquirido um bom repertório de habilidades sociais na movimentação pelo mundo real, possam fazê-lo com sucesso no mundo virtual.

Os traços narcisistas e psicóticos refletem a tendência moderna, dentro da sociedade, ao rompimento do vínculo social, em favor da identificação de estereótipos; destacam a tentativa de evitar a angústia em face de uma realidade que os jovens enfrentam cada vez de forma mais difícil; são a manifestação de uma necessidade de satisfação pulsional imediata.

As estatísticas mostram que o fenômeno está crescendo, e os resultados de estudos epidemiológicos, embora extremamente heterogêneos, têm o mérito de evidenciar o fato de que esta questão apesar de não quantificada no seio da população, é fato tangível, concreto, real, com o qual temos de lidar.

Quem sofre com isso são principalmente os jovens, que não tendo adultos com um sólido conhecimento de referência das novas tecnologias, que possam educá-los, fornecer seu exemplo e programar uma "pedagogia na e para a Internet", ou mesmo que pouco se interessam pela vida de seus filhos, uma vez que se encontram presos entre os seus projetos individuais de sucesso e conquistas (ROSA, VERAS, VILHENA, 2015), se encontram "à deriva", perdidos e confusos no uso de algo que tem fortes probabilidades de se transformar de centro de recursos infinitos, libertador, em uma prisão virtual.

Do ponto de vista filogenético, os seres humanos sobreviveram e prosperaram pelo fato de estarem juntos (família, clã, tribo, etc.) para proteção e assistência mútua: isolar-se dos outros era uma ameaça à vida, por isso o indivíduo era incentivado a viver em comunidades para a sua própria sobrevivência e, por consequência, da sobrevivência das espécies.

Solidão, neste sentido, é um sinal destinado a empurrar o ser humano em renovar as conexões necessárias para viver e prosperar. As conexões que a natureza nos pede, no entanto, não são virtuais como na realidade artificial: são as verdadeiras como as pessoas de carne e osso. De acordo com esta perspectiva, a mediação tecnológica da comunicação poderia ser uma ajuda para relacionamentos se usada com inteligência, mas nunca um substituto.

\section{POLÊM!CA $\mid$ LABORE}




\section{Referências}

BAUMAN, Z. Amor Líquido: Sobre a fragilidade dos laços humanos. São Paulo: Ed. Zahar, 2004.

BIRMAN, J. Arquivos do mal-estar e da resistência. Rio de Janeiro: Civilização Brasileira, 2006.

CASTELLS, M. A sociedade em rede - A era da informação: economia, sociedade e cultura. v.1. São Paulo: Ed. Paz e Terra, 1999.

CERTEAU, M. A invenção do cotidiano. Petrópolis: Vozes, 1994.

COLVARA, L.F. Tecnototemismo: identidades múltiplas e nova subjetividade. Conexão - Comunicação e Cultura, UCS, Caxias do Sul, v. 6, n. 11, jan./jun. 2007. Disponível em:

<http://www.ucs.br/etc/revistas/index.php/conexao/article/view/195>. Acesso em: 13 set. 2017.

DAL CIN, I.C.T.P. Dependência de internet: um estudo com estudantes e profissionais da área de TI em Belo Horizonte. Dissertação de Mestrado. Programa de Pós-Graduação em Administração. Faculdade Novos Horizontes. Belo Horizonte. 2013.

ECHEBURÚA, E.; AMOR, P.; CENEA, R. Adicción a Internet: ¿una nuevaadicciónpsicológica? Monografías de psiquiatría, n. 2, p. 38-44, 1998.

ECO, U. De Internet a Gutemberg. Conferência Accademia italiana deglistudiavanzati. USA, 1996.

FREUD, S. Psicologia das Massas e análise do Eu. São Paulo: Companhia das Letras, 1921.

[1929]. O mal-estar na civilização. São Paulo: Companhia das Letras. 2011.

GREENFIELD, D. N. Psychological characteristics of compulsive Internet use: A preliminary analysis. Cyber Psychology \& Behavior, v. 8, n. 5, p. 403-412, 1999.

LACAN, J. Televisão. Rio de Janeiro: Jorge Zahar Editor, 1974.

Discurso sobre a causalidade psíquica em Seminários. v. 1. Siglo Veintiuno Editores, 1946.

LASCH, C. A Cultura do Narcisismo: A Vida Americana numa Era de Esperanças em Declínio. Rio de Janeiro: Imago Editora, 1983.

LASCH, C. O Mínimo Eu: Sobrevivência Psíquica em Tempos Difíceis. São Paulo: Editora Brasiliense, 1984.

NÁPOLI, L. O que é o grande Outro lacaniano? Lucas Nápoli - Psicanálise em Humanes. 2014. Disponível em: <https://lucasnapoli.com/tag/grande-outro/>. Acesso em: 28 jul. 2018.

ROSA, C.M.; VERAS, L.; VILHENA, J. Infância e sofrimento psíquico: medicalização, mercantilização e judicialização. Estilos da Clínica, v. 20, n. 2, p. 226-245, 2015.

ROSA, C. M.; ZAMORA, M. H. Usos da internet: algumas reflexões ético-políticas. Revista Polêm!ca, Rio de Janeiro, v. 11, n. 4, p. 581-596, 2012.

SANCHEZ, R. Trastorno de Adicción a Internet: ¿manifestación de untrastorno de ansiedad social? - II Congresso Virtual de Psiquiatria, 2001.

SHAW, M. Y., \& BLACK, D. W. Internet addiction: Definition, assessment, epidemiology and clinical management. CNS Drugs, v. 22, p. 353-365, 2008.

\section{POLÊM!CA $\mid$ LABORE}

Polêmica - Revista Eletrônica da Uerj - Rua São Francisco Xavier, 524, $1^{\circ}$ andar

bloco D, sl.1001 • Tels.: +55 21 2334-4088/4087 • http://www.e-publicacoes.uerj.br/index.php/polemica/index http://www.labore.uerj.br • laboreuerj@yahoo.com.br 
YOUNG, K. S. Cognitive-behavioral therapy with Internet addicts: Treatment out comes and implications. Cyber Psychology \& Behavior, v. 10, n. 5, p. 671-679, 2007.

Recebido em: 25/03/2018.

Aceito em: 04/06/2018.

\section{POLÊM!CA $\mid$ LABORE}

Polêmica - Revista Eletrônica da Uerj - Rua São Francisco Xavier, 524, $1^{\circ}$ andar bloco D, sl.1001 • Tels.: +55 21 2334-4088/4087 • http://www.e-publicacoes.uerj.br/index.php/polemica/index http://www.labore.uerj.br • laboreuerj@yahoo.com.br 